\title{
SEIS HISTÓRIAS DO PENSAMENTO ECONÔMICO: ABORDAGENS DADAS À REVOLUÇÃO MARGinAlista E AO PENSAMENTO DE NASSAU SENIOR
}

\section{Adriana Sbicca $^{1}$}

\section{INTRODUÇÃO}

Este trabalho apresenta uma análise comparativa de alguns manuais de História do Pensamento Econômico (HPE). O intuito é discutir como os autores destes livros explicitam diferentes objetivos e posturas frente à HPE e vão se diferenciar na apresentação de um evento na história das idéias econômicas e no tratamento dado ao pensamento de um determinado autor. Para tanto, escolheu-se a Revolução Marginalista como o evento a ser estudado e o pensamento de Nassau Senior. Os livros-texto de HPE foram selecionados pela sua grande utilização nos cursos de graduação de Economia no Brasil: "História do Pensamento Económico" de Mark Blaug, "História do Pensamento Econômico" de E. K. Hunt, "O Pensamento Econômico em Perspectiva - uma história crítica" de J. K. Galbraith, "História do Pensamento Económico" de Henri Denis, "História do Pensamento Econômico" de I. H. Rima, "História da Análise Econômica" de J. A. Schumpeter. O trabalho envolve: i) expor a abordagem que os autores dos livros pretendem seguir; ii) verificar a diversidade dos livros de HPE ao tratarem da Revolução Marginalista e do pensamento de Nassau Senior; iii) Apresentar algumas considerações sobre a influência da abordagem pretendida pelos autores dos manuais sobre o tratamento dado aos dois temas; iv) apresentar uma reflexão sobre o ensino de HPE.

\footnotetext{
${ }^{1}$ Professora do Departamento de Economia da UFPR.
} 


\section{CRITÉRIOS PARA A ESTRUTURA DOS LIVROS-TEXTO E A ABORDAGEM DOS TEMAS}

Blaug, Hunt, Galbraith, Denis, Rima e Schumpeter apresentam critérios diferentes tanto para a seleção dos autores de que tratam ao longo de suas obras, como para a determinação do espaço e da ênfase dados a cada tema.

No prefácio da $2^{\mathrm{a}}$ edição, Blaug acentua sua crença em que a história do pensamento econômico é a história de uma análise prévia "e orientada pelo desejo de refinar, aperfeiçoar, melhorar". Afirma que a ciência econômica se constituiu numa disciplina acadêmica a partir de 1870, quando a transmissão das idéias passa a dominar o movimento da mesma, a qual passa a ser caracterizada por uma procura implacável pela verdade. Neste sentido, Blaug (1962, 1 v., p. 36) afirma que a verdade "reside largamente nas contribuições graduais para o avanço do conhecimento econômico". Reforçando seu pensamento, diz que os instrumentos analíticos têm sido aperfeiçoados e acrescentados, cada vez mais dados empíricos têm sido reunidos e classificados para a verificação de hipóteses econômicas e o sistema econômico é mais compreendido que anteriormente. Daí Gianneti da Fonseca (1994, p. 566) afirmar que Blaug comenta e avalia pensadores do século XVIII e XIX como um "presente espúrio" pois procura reconstruir "o passado de modo 'racional', ou seja, como se ele não passasse de uma versão empobrecida, ainda ingênua, do que veio a se tornar a economia acadêmica anglo-americana no pós-guerra". Fonseca chama esta atitude de falácia anacronista.

Hunt (1989) esclarece no prefácio a importância de tratar de seu critério de seleção para estruturar seu livro. O autor assume-se marxista e, para mostrar o significado disto, apresenta na introdução do livro algumas características dessa postura. Neste sentido, adota a interligação entre teorias sociais e processos sócio-históricos. Alega, por um lado, que as idéias são produto das circunstâncias econômicas e sociais em que são concebidas. E, por outro lado, elas influenciam a história pois as pessoas agem sobre as circunstâncias com base na idéia que têm delas. Dessa forma, Hunt chama a atenção para o momento em que os autores de HPE escreveram e a necessidade de se recolocar o autor em seu contexto para compreender o surgimento e o desenvolvimento das idéias. Quanto aos objetivos que orientam o livro diz: “....ao escrever este livro, tentei lançar luz sobre a natureza das controvérsias contemporâneas sobre teoria econômica, examinando seus antecedentes históricos." (HUNT, 1989, p. 21). Blaug e Hunt esclarecem opções que fizeram ao escrever o livro e que os orientaram nessa tarefa. A opção de 
Blaug está no âmbito da metodologia da ciência, mais precisamente o falseacionismo popperiano, e a de Hunt, numa linha do pensamento econômico que possui uma forma característica de estudar a economia a partir do materialismo dialético: o marxismo.

Galbraith, assim como Hunt, chama a atenção para a relação entre contexto e idéias. Mas faz isto de uma maneira mais enfática pois para ele as idéias não têm vida própria. Inicialmente propõe não se ater a detalhes e chama a atenção para o que o norteará em seu texto: a dominância das idéias (sejam elas certas ou erradas) e sua importância. Tem por objetivo apresentar aqueles pensamentos econômicos que mantêm seu interesse em nossa época e não se ater "ao que é perfeitamente descartável". Passa, então a enumerar problemas que se relacionam à forma como a HPE tem sido apresentada. Para ele, "grande parte do que foi escrito sobre a história das idéias econômicas é agressivamente enfadonho" (GALBRAITH, 1989, p. 2), mas acha possível tratar a HPE de modo diferente e é o que pretende fazer. Galbraith (ibid., p. 3) afirma que "As idéias centrais e o seu contexto são vivamente interessantes e o meu interesse tem se mantido desperto há mais de meio século". Acrescenta:

Nada tenho contra a inclusão ocasional de detalhes periféricos à evolução do pensamento econômico se isso ajudar a tornar a história mais interessante. Mas meu principal interesse é isolar e enfatizar a idéia ou idéias centrais de cada autor, escola ou período específico, e enfocar sobretudo aqueles que continuam a ter uma ressonância moderna. Quanto àquilo que se revelou transitório [grifo nosso], eu procuro escrupulosamente ignorar, assim como tento evitar qualquer tipo de estudo da corrente principal da economia que não tenha alterado ou flectido a corrente em si [grifo nosso]. (GALBRAITH, 1989, p. 3)

Galbraith não especifica o que compreende por "importante", "relevante" e "interessante". Apesar disso, acusa os autores de HPE que não fizeram uma "boa seleção" de assim terem procedido não pela dificuldade em fazê-lo mas por "buscarem excelência acadêmica ou por terem receio de críticas" (GALBRAITH, 1989, p. 1). Chamamos a atenção para a palavra "transitório" pois dá um significado ao trecho de Galbraith que se assemelha à noção de progresso das idéias sustentada por Blaug, de história do pensamento como um refinamento da disciplina na medida em que as contribuições importantes parecem ser aquelas que permanecem (que não são transitórias). É obscuro o critério de seleção utilizado por Galbraith de acordo com a influência exercida pela idéia, entretanto, o autor admite, em nota de rodapé: 
E passo por cima dos grandes alemães do século passado que escreveram sobre história econômica mas que tiveram pouca influência sobre seu curso - embora eu deva confessar que me falta aqui um certo interesse motivador. (GALBRAITH, 1989, p. 3)

Assim, após procurar convencer o leitor de que a HPE tem se tornado enfadonha e obscura porque 'o critério da importância não é obedecido', ele confessa uma influência pontual de algo próprio a ele, subjetivo, ou um tratamento menos detalhado à parte da história por razões de interesse motivador pessoal.

Segundo Henri Denis, o fio condutor de sua obra é a concepção de ser humano que permeia o pensamento econômico. Para compreender melhor sua proposta, afirma que a Grécia Antiga foi o berço da nossa civilização pois nela o homem toma consciência de ter uma vida política, quando se vê como membro de um corpo social. Como reflexo disto, das 782 páginas de seu livro, 46 delas são destinadas à Grécia contra nenhuma em Blaug e em Hunt. A Renascença é apresentada como um período em que a concepção de ser humano muda e assume um caráter naturalista que tende a admitir que o homem não passa de um animal superior. Segundo Denis, esta idéia é em larga medida usada por autores dos séculos XVIII e XIX, que lançaram as bases da economia política e é partilhada por aqueles que querem construir a ciência econômica como uma ciência exata. Por fim, diz que a concepção naturalista é posta em causa por Marx que vai ser influenciado pela filosofia grega e pelo naturalismo moderno (este em seu materialismo). Portanto, Denis propõe um critério que nasce da própria história do pensamento econômico como forma de caracterizar etapas com diferentes concepções de ser humano, o que sugere uma certa linearidade e organização intrínseca à própria HPE. Outro elemento que se destaca em seu texto é a falta de qualquer discussão sobre a posição ideológica do autor, seja com relação a sua identificação com uma corrente da HPE (como em Hunt) ou diante da metodologia da ciência (como faz Blaug). Tal ausência se assemelha à postura de Galbraith e pode ser observada também em Rima.

Rima não trata muito de sua abordagem da HPE. Afirma que a estrutura de seu livro se baseia numa apresentação cronológica do desenvolvimento dos instrumentos e conceitos analíticos que compreendem a massa da teoria econômica (RIMA, 1977, p. 19). No entanto, em seu epílogo (ibid., p. 584) podemos encontrar menção à HPE que pode ter influenciado sua abordagem. São apresentadas algumas controvérsias de interesse metodológico com relação ao uso da matemática na economia, à questão 
indução versus dedução e ao papel do economista teórico como formulador de políticas. Rima apresenta estes pontos com o objetivo de estimular a leitura e os pensamentos futuros do leitor, embora ele não se posicione diante destas questões. Como em Denis, não há menção a posturas que o teriam influenciado na forma de estruturar e de escrever o livro-texto. Rima chama atenção para a inexistência de uma verdade no pensamento econômico já que sob certas circunstâncias da época toda teoria tem um pouco de verdade. Assim, indiretamente chama atenção para a relação entre contexto e as idéias. Um exemplo disto pode ser encontrado na observação sobre Keynes e Marx que segue:

Se suas idéias [de Marx e Keynes] estivessem substancialmente fora de diapasão com os requisitos do meio ambiente, elas teriam sido postas de lado; sobrevivem e são influentes porque o ambiente é hospitaleiro para elas. (RIMA, 1977, p. 597)

O título do livro de Schumpeter é "História da análise econômica" e esta "...trata das questões referentes a como as pessoas se comportam em qualquer tempo e quais são os efeitos econômicos resultantes de eles agirem assim..." (SCHUMPETER, 1964, v. 1, p. 43-44). Zerkowski(1987) afirma que na intenção de descrever e de interpretar os instrumentos analíticos desenvolvidos ao longo da história do pensamento econômico, Schumpeter admite ao mesmo tempo que "O meio ambiente, conquanto força favorável ou inibidora (...), é um personagem paralelo, no dizer de Schumpeter um herói que permanecerá ao longo da nossa peça." (ibid., p. 127). Segundo Zerkowski (ibid.), "O que Schumpeter tenta é desentranhar o instrumento e submetê-lo ao crivo da história”. Schumpeter afirma que a análise científica não é

(...) um processo logicamente consistente que se inicia com algumas noções primitivas que se adicionam linearmente a um conjunto preexistente. Não é também, simplesmente, a descoberta progressiva de uma realidade objetiva - como o é, por exemplo, a descoberta de acidentes geográficos. Mais exatamente, é uma incessante luta com criações de nosso próprio espírito e de nossos predecessores e progride - quando o faz em ziguezague, não como uma lógica, mas como um impacto de novas idéias, observações ou necessidades, e também segundo as propensões e temperamentos de novos homens. (SCHUMPETER, 1964, 1 v., p. 25) 
Dessa forma, diverge de Blaug por não propor um progresso científico certo. Apesar de não esclarecer se segue alguma metodologia científica, seu modo de pensar a ciência tem elementos semelhantes a Kuhn, como pode ser percebido no trecho a seguir:

\begin{abstract}
Realmente nosso principal objetivo é descrever o que podemos denominar o processo da Filiação das Idéias Científicas - o processo pelo qual o esforço dos homens para compreender o fenômeno econômico produz, aperfeiçoa e destrói as estruturas analíticas numa sucessão interminável. E - o que é também uma das principais teses a serem verificadas neste livro - que fundamentalmente este processo não difere dos processos análogos, utilizados nos outros campos do conhecimento. (SCHUMPETER, 1964, 1 v., p. 26-27)
\end{abstract}

Schumpeter não poderia propor uma HPE no sentido de contribuições graduais para o avanço da ciência, como faz Blaug, sob pena de ser inconsistente. Propõe que

(...) os hábitos científicos ou regras de procedimento não existem meramente para ser julgados por padrões lógicos que lhes são independentes; contribuem em algo, pelo menos, para êstes padrões. Extrapolando-se, conclui-se que se poderá inferir, da observação e formulação do processo científico, uma espécie de lógica descritiva e pragmática - que envolve, ou incorpora, o estudo da história das ciências. [grifo no original] (SCHUMPETER, 1964, p. 26, 1 v.)

Schumpeter busca inferir uma espécie de lógica descritiva. Não assume, portanto, que a HPE já possua uma lógica intrínseca, como fazem Blaug e Denis, cada um a seu modo. Schumpeter propõe como um de seus principais objetivos determinar a relatividade histórica na análise econômica. Neste sentido afirma que

... a Análise Econômica e seus resultados são, sem sombra de dúvida, afetados pela relatividade histórica e a questão única é saber-se o quanto. Nenhuma resposta conveniente a esta questão pode ser obtida filosofando a seu respeito, mas será uma de nossas mais importantes preocupações determiná-la por intermédio de investigação pormenorizada. (SCHUMPETER, 1964, 1 v., p. 35). 


\section{O PAPEL DA IDEOLOGIA NA HPE}

Um aspecto merecedor de análise é o tratamento dado à relação entre ideologia e o pensamento econômico. Inicialmente devemos ressaltar dois significados atribuídos ao termo. O primeiro vincula o significado de "ideológico" a não-objetivo, falso, imbuído de valor, ilusório, normativo, político, burguês, moralista. Caberia neste caso a questão: seria a economia uma ciência ou meramente uma "ideologia"? (MILBERG, in DAVIS et al., 1998, p. 243-245). A palavra meramente explicita o sentido pejorativo e "ideológico" é colocado como oposto a científico. No entanto, no século XX o sentido do termo ideológico assume um significado diferente em que todo conceito ou categoria de análise social está imbuída de crenças e normas, a despeito de sua objetividade (ibid.). Neste sentido, admite-se que os constructos sociais incorporam nossa interpretação de vida social.

Os autores dos livros de HPE estudados nem sempre explicitam o conceito assumido de 'ideologia'. Podemos perceber qual é adotado algumas vezes, mas é necessária a leitura atenta e crítica para isso. Rima e Denis não tratam do papel das ideologias na ciência e especificamente na HPE. Galbraith, por sua vez, sustenta a possibilidade da postura imparcial do historiador econômico:

O que dizer da natureza e eficácia do capitalismo, da livre iniciativa, do estado de bem-estar social, do socialismo e do comunismo? Com estas questões, vale notar, o estado de espírito da economia sofre uma mudança bastante fundamental. Ela deixa de ser uma disciplina imparcial, desapaixonada e supostamente científica para tornar-se palco de argumentos expressos com ardor e veemência. O mais neutro dos estudiosos, o empresário de espírito mais ostensivamente prático, o político menos sujeito a qualquer processo intelectual restringente, todos reagem com visível e violenta emoção. Mas tal reação a história, entretanto, buscará evitar. (GALBRAITH, 1989, p. 7)

No trecho transcrito acima Galbraith quereria dizer que a economia é uma disciplina imparcial? Esta pode ser a interpretação do trecho lido até a sua terceira linha. No entanto, ao final do trecho o autor diz que a história buscará evitar tais questões que tornam a economia parcial, o que reflete, pode-se interpretar, uma dificuldade em tal tarefa, mas a possibilidade de realizá-la. 
Blaug e Hunt apresentam suas posições diante da HPE que, afirmam, influenciarão nos seus escritos. Elas são diferentes e isto tem origem no fato de Blaug seguir o falseacionismo de Popper e Hunt ser marxista. Existem críticas mútuas dessas linhas de pensamento e um exemplo é que o próprio Popper constrói críticas aos marxistas através de seu trabalho "A sociedade aberta e seus inimigos" (1945), onde as duas formas de abordar a ciência são contrapostas. ${ }^{2} \mathrm{O}$ juízo de valor, para Hunt, está presente na ciência não sendo possível dissociá-los. Para ele, há o comprometimento vital dos economistas com questões morais, políticas, sociais e práticas (HUNT, 1989, p. 22). O valor se refletiria na opção que se adota para algumas características do capitalismo como harmônico ou conflituoso, estável ou instável. E se relaciona também à própria aceitação ou não da propriedade do juízo de valor na ciência. Contra isto se opõe Blaug, que cita a ideologia e afirma que "A tarefa do historiador do pensamento econômico é mostrar como pressupostos definidos conduzem a certos tipos de análise e em interrogar-se se estas análises permanecem válidas quando desprovidas do seu fundamento ideológico." (BLAUG, 1990, 1 v., p. 38). Assim, "os enviesamentos meta-econômicos têm sido repetidamente revelados e separados do corpo das proposições verificáveis com as quais se relaciona" (ibid., p. 40). Deste modo, "a ciência econômica está constantemente a eliminar os enviesamentos do passado" (ibid., p. 39). Desta maneira é que Blaug pode sustentar a idéia de progresso na ciência por que acha possível separá-la de ideologias que poderiam afastá-la da objetividade.

Schumpeter acredita que a ideologia está presente no pensamento dos autores, mas afirma:

Relembremos: ocasionalmente, pode ser de interesse responder por que uma pessoa diz o que diz; mas qualquer que seja a resposta, não nos diz nada sobre se o que se afirma é verdadeiro ou falso. Não utilizaremos os métodos fáceis da luta política infelizmente muito comum também entre os economistas - de discutir a respeito de uma proposição atacando ou defendendo

2 A crítica de Popper centra-se nas formas de historicismo que, segundo ele, é uma doutrina que reconhece leis gerais da evolução histórica, que a convertem em algo inteiramente determinado e previsível. Neste sentido diz: "A tarefa que Marx se propôs em $O$ capital foi a de descobrir leis inexoráveis do desenvolvimento social" (POPPER, 1980, p. 155). Em outro trabalho intitulado A miséria do historicismo, Popper aponta dois falsos pressupostos naturalistas: o de que a evolução histórica deve ser tão determinada quanto a biológica e o de que uma ciência da história deve recorrer ao método das ciências naturais (regularidades entre fenômenos). 
os motivos daquele que a apresenta ou o interesse a favor ou contra o qual a proposição parece referir-se. (SCHUMPETER, 1964, 1 v., p. 32)

Estas palavras se chocam com a posição de Hunt, que não acredita na possibilidade de se dissociar juízo de valor da economia e que o faz apresentar, muitas vezes, pensamentos da HPE que têm como motivação principal interesses individuais e de classe. É comum sua interpretação, ao longo de seu livro-texto, de que alguma idéia é sustentada pela procura de manutenção de status quo.

\section{O PENSAMENTO DE NASSAU SENIOR NOS LIVROS-TEXTO}

A tarefa de encontrar o pensamento de Senior presente nos livros foi mais fácil com a existência de índice que mostrasse as referências feitas aos autores e grupos teóricos (como em Denis, Hunt e Galbraith). Quando o livro apresentava nos títulos dos capítulos os nomes dos autores da HPE (principalmente aqueles que procurávamos) ou um elemento que levava facilmente ao reconhecimento de que autor de HPE se tratava (como Rima) foi ainda mais simples do que nos livros que eram organizados de acordo com temas e faziam menção a diversos autores de correntes teóricas e épocas diferentes nos capítulos (o caso de Schumpeter) ${ }^{3}$ ou que traziam títulos de capítulos que não remetiam diretamente a determinado autor ou escola (alguns capítulos de Galbraith).

O espaço destinado a Senior é bastante diverso. Não foi encontrada nenhuma referência a este autor em Denis. Em Galbraith o espaço utilizado para tratar de Senior é pequeno, apenas uma menção na página 95 , onde diz que Senior propôs a primeira solução para o problema do retorno da origem dos lucros e juros. Acrescenta que esta proposta manteve-se por quase meio século e envolvia a abstinência de um prazer, sendo o lucro o custo de se conseguir esta abstinência. Ressalta-se que a estrutura do livro dificulta o encontro de referências já que existem capítulos denominados, por exemplo, "O crepúsculo e sino vespertino" (capítulo XX) e "Confirma-

3 Zerkowsfi (1987, p. 123) afirma que a History segue em suas linhas mais amplas uma trajetória cronológica, ao mesmo tempo que os protagonistas principais "atropelam, por assim dizer, o tempo, e de repente voltam ao cenário. Problemas de editoração à parte, o sentido didático de Schumpeter é o de recapitular para poder prosseguir e fazer as ligações no tempo. A isto ele chama de 'revista às tropas'". 
ção por Marte" (capítulo XVIII), embora o autor tenha chamado atenção para que a leitura deveria ser feita integralmente, do início até o fim do livro.

Os títulos dos capítulos do livro de Blaug apresentam os nomes dos autores e não há Senior e nem um subtítulo num capítulo que se refira à influência de Senior sobre outro autor. Foi encontrada uma menção a Senior no Post-Scriptum Metodológico (1990, vol. 2, p. 497) quando Blaug se refere aos metodologistas que aceitaram a demarcação de ciência definida por Popper (falseabilidade das teorias) mesmo que realçassem outras questões ao invés dos testes empíricos.

Temos, então, um espaço bastante diferenciado para se tratar de Nassau Senior. Denis não se refere a Senior. Blaug e Galbraith fazem menção a ele, o primeiro ressaltando a compatibilidade entre a metodologia proposta por Senior e sua posição popperiana, e o segundo se referindo à sua proposta para o retorno dos lucros e juros. Rima, Hunt e Schumpeter tratam de maneira mais abrangente de Nassau Senior. Hunt utiliza um espaço relativamente grande: 14 páginas das 541 e Rima trata de Senior em 5 páginas das suas 597. Schumpeter estrutura seu livro de maneira a dispersar as referências a um determinado autor. Assim, há muitas referências breves a Senior, exceto pelo subtítulo "as contribuições de Senior" onde Senior é apresentado de maneira explícita em duas páginas. Em Rima, Senior é apresentado no capítulo 8 juntamente com John Stuart Mill sob o título "Maioridade do classicismo", sem maiores comentários quanto ao que significaria este subtítulo de seu ponto de vista. Hunt o apresenta junto com Bentham e Say, tendo como título do capítulo "O subjetivismo racionalista: a economia de Bentham, Say e Senior".

Das referências feitas a Senior, sejam breves como aquelas feitas por Blaug e Galbraith ou o tratamento mais atento dado por Schumpeter e Hunt, podemos ressaltar dois elementos que são mais lembrados: sua proposta metodológica e sua explicação da origem dos retornos dos lucros e juros.

\section{A METODOLOGIA PROPOSTA POR SENIOR}

Uma comparação do pensamento de Nassau Senior apresentado pelos autores dos livros-texto revela que a contribuição à metodologia da ciência econômica é citada por Blaug, Hunt, Rima e Schumpeter. O primeiro, não explicita a idéia de Senior, mas a chama para reforçar seu ponto de vista popperiano. Rima (1977, p. 188) chama Senior de o primeiro dos teoristas 
puros da Inglaterra pois seus esforços se davam no sentido de apresentar a Economia como um grupo de generalizações deduzidas de um pequeno número de postulados. Este comentário remete à controvérsia de interesse metodológico apresentada por Rima entre o dedutivismo e indutivismo.

Hunt e Schumpeter se aprofundam mais neste assunto e explicitam o pensamento de Senior ao apresentar e discorrer sobre seus quatro postulados, sobre os quais é elaborado seu pensamento econômico. Hunt cita duas obras de Senior: Three lectures on the rates of wages (1930) onde o fundo de salários é proposto no prefácio e An outline of the science of political economy (1836) que traz uma apresentação da metodologia de Senior no primeiro capítulo. De acordo com esta metodologia de Senior, o economista deveria se preocupar com a análise da riqueza e não com o bem-estar social. Isto porque temas como bem-estar envolveriam proposições normativas e éticas que refletem diferentes interesses e por isso havia conflito nas teorias de economia política. Após a eliminação destas proposições sobrariam princípios empíricos claramente estabelecidos da vida econômica. Senior procurava uma ciência pura despida de valores. Hunt cita Senior: "Já dissemos que os fatos gerais e que se baseia a Economia Política compreendem umas poucas proposições gerais, que são o resultado da observação ou da consciência" (HUNT, 1989, p. 162 apud SENIOR) ${ }^{4}$. Hunt critica esta tentativa de Senior por ele não sustentar que a elaboração de uma teoria social requer abstrações. Para Hunt, ao se construir uma teoria, ignoram-se certos elementos e isolam-se outros e a experiência não confere facilmente proposições gerais que sejam de importância crucial. Hunt chama a atenção para o fato de que o conceito de importância depende do problema proposto e dos valores do teórico.

Schumpeter (1964, 2 v., p. 134), por sua vez, salienta como um feito de Senior a pretensão em unificar e apresentar a teoria econômica de acordo com as exigências de um método postulativo (ou seja, série de 4 postulados induzidos) e o chama de o primeiro teorista "puro" do período, se bem que o resultado de sua proposta esteja longe da perfeição. Posteriormente (ibid., p. 198), Schumpeter inicia uma discussão sobre a influência dos economistas em J. S. Mill e cita Senior como um dos economistas deste período que sentiu necessidade de apresentar uma definição para a ciência econômica, o que realçaria a autonomia da Economia. Critica estas definições por não serem específicas em relação aos fatos e problemas que devem ser objeto desta ciência. Schumpeter chama a atenção para que Senior era o mais explícito em distinguir a "ciência" da economia (discussões sobre o que é) da "arte" da

4 An outline of the science of political economy (1836, p. 26). 
Economia (o que deveria ser), ou de perceber o "vício ricardiano", como denominou Schumpeter. Querendo dizer que "os problemas de política econômica envolvem sempre tantos elementos não-econômicos que não devem ser tratados com base em considerações puramente econômicas" (SCHUMPETER, 1 v., 1964, p. 202). Schumpeter apresenta uma análise de Senior quanto ao espaço que ele deve ter na HPE e discorre sobre sua genialidade colocando-o como equivalente em importância a Ricardo. Argumenta que ele não conquistou um lugar como este último por às vezes proferir tolices e não possuir o mesmo "pedestal de reputação".

\section{OUTRAS CONTRIBUIÇÕES DE SENIOR}

O pensamento de Senior mais lembrado pelos historiadores é quanto à explicação da origem do lucro. Galbraith, Schumpeter, Hunt e Rima tratam deste aspecto. Hunt denominará este pensamento de Senior como "a justificativa intelectual e moral para o lucro e a renda da terra". Schumpeter e Rima apontam como uma das contribuições de Senior o uso do conceito de abstinência na teoria do capital e seu rendimento. Estes detalham o significado de abstinência em Senior. Neste sentido, Schumpeter se refere à teoria do capital pela abstinência e faz uma ressalva à originalidade de Senior pois argumenta que o mesmo apenas trouxe "à baila uma tendência doutrinária existente" (SCHUMPETER, 2 v., 1964, p. 313). Rima vincula a teoria da abstinência de Senior (assim denominada por Rima) à sua teoria do valor porque acrescenta ao custo da produção o custo do capital, além da mão-de-obra. Schumpeter também comenta isso (ibid., p. 311) com o subtítulo "As contribuições de Senior". Aponta o terceiro postulado de Senior: "As forças do Trabalho e dos outros instrumentos que produzem riqueza podem ser indefinidamente aumentadas pela utilização de seus Produtos como meios de incrementar a produção" (ibid., p. 311) e analisa esta proposição como um aprimoramento de Ricardo por acrescentar "os outros instrumentos que produzem riqueza".

Hunt dá um outro enfoque a esta idéia de Senior. Na introdução do capítulo, Hunt chama a atenção para características do sistema capitalista e a percepção que as pessoas tinham desse sistema. Essa preparação para tratar das idéias de Senior torna-se importante na medida em que será a base para Hunt formular comentários que são bastante diferenciados daqueles feitos por Rima e Schumpeter. Hunt passa a relatar a distinção entre a teoria do valor-trabalho (ou perspectiva da produção) e a teoria do valor-utilidade (perspectiva do mercado). De modo recorrente, o livro trata de contrapor 
esses dois conjuntos de teorias incorporando os autores em um ou outro. Senior será incorporado à teoria do valor, utilidade. O primeiro subtítulo do capítulo que enfoca Senior é denominado "Origens sociais das premissas da teoria da utilidade" e descreve os "fundamentos intelectuais da teoria da utilidade": (i) a consciência de condições humanas especiais provocadas pelo modo de produção capitalista e (ii) a generalização e projeção universal destas condições "como características profundas, inalteráveis e naturais de todos os seres humanos em todas as sociedades" (HUNT, 1989, p. 143). ${ }^{5}$

Hunt critica, então, a posição utilitarista pois, através da visão de homem adotada, acaba por não discutir a distribuição de renda e não aceita que a classe trabalhadora arcou com os custos da industrialização. Afirma: "onde uma pequena classe capitalista possui e controla os meios de produção, isto quer dizer que os lucros têm que aumentar em relação aos salário" (HUNT, 1989, p. 145). Segundo Hunt, quando se admite como natural o capitalismo, a visão é de que os capitalistas arcaram com os custos de sua construção já que a acumulação de capital é financiada com os lucros. Esquece-se a dotação inicial de fatores.

Senior é apresentado como formulador de idéias que posteriormente seriam usadas para "dissociar os conceitos de harmonia social e benefício social do mercado sob a perspectiva da teoria do valor-trabalho, dissociação que Smith e Ricardo não tinham conseguido fazer.

Primeiramente Hunt trata da "orientação social de Nassau Senior" (subtítulo dado a esta parte do livro-texto). Senior é apresentado como tendo selecionado certas idéias de economistas clássicos anteriores, modificado-as e acrescentado as suas próprias para "apresentar uma justificativa coerente do status quo do capitalismo do século XIX”. Aqui percebemos que Hunt dá a entender que Senior buscava consciente e objetivamente construir esta justificativa.

5 Tais características se referem a: i) Especialização do trabalho e o isolamento do produtor que o faz se sentir como parte integrante de um todo sócioeconômico interdependente. A origem destas idéias estaria em Thomas Hobbes e sua crença de que toda motivação humana é auto-interesse. Sendo assim, para que não ocorresse o "estado natural de guerra" deveria haver um governo central, segundo Hobbes. Para Hunt, os utilitaristas teriam substituído este governo central pela "mão invisível" do mercado; ii) egoísmo e o caráter competitivo da natureza humana são incorporados na idéia do desejo pelo prazer e de se evitar a dor; iii) Esta visão de homem leva a tratar o mercado como uma instituição universalmente benéfica pois a troca gerabenefícios aos participantes. A harmonia torna-se uma característica natural em contraposição ao conflito de classes que geralmente caracteriza a teoria do valor trabalho; iv). Outra conseqüência foi a generalização para as outras classes sociais do comportamento do capitalista: calculista, racional que procura maximizar os lucros (HUNT, 1989, p. 147). 
$\mathrm{Na}$ apresentação do contexto das idéias de Senior, Hunt fala da reação da classe trabalhadora diante de dificuldades trabalhistas na Inglaterra que tinham levado esta classe a um nível de vida "subumano de exploração e degradação". Aqui Hunt legitima o movimento dos trabalhadores e tira a legitimidade das idéias de Senior que "assustado com a reação dos trabalhadores" (greves generalizadas, tumultos, sabotagens) teria proposto o "fundo para manutenção dos trabalhadores". Quando este fundo fosse adotado, o salário aumentaria ou diminuiria de acordo com uma melhora ou piora da produtividade deste trabalhador, variável que define a participação do trabalhador no fundo de salários formado pelos capitalistas. A produtividade do trabalho poderia ser aumentada com a abolição das leis dos pobres que tinham dado direitos aos trabalhadores e estavam em desacordo com o contrato entre trabalhadores e capitalistas. Pois os salários deveriam representar o livre jogo das forças de oferta e demanda e não a necessidade do trabalhador. Senão, haveria fome, peste e guerra civil.

Para Hunt, as idéias de Senior surgem numa época em que está aumentando a influência do pensamento de Owen, Hodgskin e Thompson. Tais idéias socialistas foram chamadas por Senior de "Economia Política do Pobre" e, segundo ele, exerciam atração natural sobre aqueles sem instrução. Segundo Hunt, em 1832 Senior estuda as "leis da pobreza" e edita uma nova, em 1834, que altera a assistência aos pobres numa tentativa de evitar que os mesmos caíssem na tentação de não trabalhar e gerar mais pobres.

\section{A RevoluÇão MARginalista}

Rima, Denis, Blaug, Schumpeter e Hunt focam o redescobrimento do conceito marginal por Jevons, Menger e Walras. Deste modo, diferentemente do tratamento dado ao pensamento de Senior, há uma maior presença da contribuição das idéias marginalistas ocorrida por volta de 1870. Diferem, no entanto, com relação ao tratamento dado aos três autores supracitados, tanto com relação à interpretação do pensamento deles (principalmente se apresentam um caráter de conteúdo novo ou apenas uma nova forma que salienta o uso da matemática) quanto ao significado de tais idéias na teoria econômica (o que pudemos perceber nas reflexões em torno do adjetivo "revolucionário" muitas vezes usado ao se tratar do assunto). Ao focar a Revolução Marginalista (chamaremos assim o pensamento de Jevons, Menger e Walras, mesmo que nem todos os autores o façam, como veremos) procuramos salientar o tratamento dado à emergência simultânea (ou prati- 
camente) de idéias em torno do conceito marginal por três autores diferentes em países diferentes. Este aspecto pode servir como um exemplo histórico interessante para a reflexão em torno da característica internalista ou externalista das idéias. A primeira salienta o fato de que o pensamento econômico se refere a uma situação-problema particular e deve ser entendido como uma resposta a questões econômicas surgidas na sociedade, independente do desdobramento interno da própria ciência econômica (FONSECA, 1994, p. 558). Já a segunda se refere à evolução interna da própria economia enquanto disciplina científica. Os autores que adotam mais esta primeira posição costumam reconstruir o caminho da teoria econômica identificando contribuições decisivas para o avanço do conhecimento e preparando terreno para a compreensão dos passos que virão. Já os autores que costumam utilizar a posição externalista costumam sentir a necessidade de apresentar e recolocar o autor em seu contexto, levando em conta que a ciência econômica lida com uma realidade mutante que influencia as idéias (FONSECA, 1994).

Blaug é quem mais discute o significado "revolucionário" do marginalismo e as possíveis explicações para a simultaneidade dos três trabalhos que sustentam o conceito marginal. $\mathrm{O}$ autor afirma que a contribuição destes três autores não poderia ser explicada na forma "criptomarxista", em termos de evolução de estruturas produtivas, ou da relação entre classes sociais, porque os contextos de Manchester, Viena e Lausanne eram muito diversos. Também, segue Blaug, trabalhos anteriores destes autores revelavam recomendações práticas diversas. Por fim, não se tinha consciência de que se estava vivendo uma crise da teoria econômica a ponto destes autores terem sido impulsionados por uma procura de alternativa. Blaug, então, vai propor uma outra forma para tratar a questão. Discute quatro possibilidades para seu surgimento: desenvolvimento intelectual autônomo no interior da disciplina; resultado de correntes filosóficas; resultado de alterações institucionais específicas na economia; e reação face ao socialismo, em particular frente ao marxismo. Chega à conclusão de que a idéia de "revolução marginalista" é um exemplo acabado do tipo de reconstrução racional da história do pensamento econômico que vai dar origem a falsos enigmas históricos e acarretar confusão entre as origens da revolução (se é que houve uma, o autor acrescenta) e a explicação de seu sucesso em influenciar o pensamento econômico posterior (BLAUG, 1990, v. 2, p. 18).

Em suas reflexões, Schumpeter discute o alcance da "revolução" de Jevons, Menger e Walras em criar um novo aparelho de análise (SCHUMPETER, 1964, v. 3, p. 102). Propõe duas questões: "Em que sentido foi efetuada uma Revolução? Produziu esta Revolução uma nova teoria do processo econômico?" Com relação à primeira questão, Schumpeter respon- 
de de maneira afirmativa, desde que revolução seja entendida como "uma modificação que seja total e descontínua”. Sendo assim, houve uma revolução da teoria pura da economia na medida em que Schumpeter observa a teoria da utilidade de Jevons e Menger como uma teoria embrionária do equilíbrio geral walrasiano, como "princípio unificador que se encontra na base de qualquer sistema de equilíbrio" (ibid., p. 197). Quanto à segunda questão, Schumpeter responde negativamente pois "nenhuma teoria pura poderá jamais ser uma teoria no sentido de uma análise completa dos fenômenos aos quais se refere" (ibid., p. 198). Aqui Schumpeter está se afastando do "vício ricardiano" que denunciou e adota um critério diferente daquele utilizado, por exemplo, por Hunt.

Quanto ao significado para a teoria econômica do pensamento dos três autores, Hunt afirma que

Não há dúvida de que, por terem eles sido os primeiros pensadores a propor uma teoria do valor coerente com a visão da perspectiva filosófica utilitarista, os economistas conservadores consideraram suas teorias como uma "revolução" no pensamento econômico, referindo-se à década de 1870 como uma separação de águas entre a Economia clássica antiquada e a Economia neoclássica moderna e científica. (HUNT, 1989, p. 279).

E complementa que "o grande significado das idéias de Jevons, Menger e Walras estava em como eles mudaram a forma da economia utilitarista e não em qualquer grande mudança de conteúdo" (HUNT, 1989, p. 279), ao se referir ao modo como o marginalismo permitiu o uso da matemática e do cálculo diferencial especificamente. Ao relacionar o conceito de utilidade marginal com harmonia no capitalismo, Hunt é irônico como se percebe neste comentário sobre Jevons:

Mais uma vez, a perspectiva da utilidade tinha conseguido uma nova maneira de se encarar a 'mão invisível', que, agora, com a nova formulação 'científica' e 'matemática' poderia, comprovadamente, maximizar a utilidade para todos, num mundo de fraternidade e harmonia" (HUNT, 1989, p. 284).

E segue:

As diferenças fundamentais entre a perspectiva da teoria da utilidade e a perspectiva da teoria do trabalho já estavam claras antes de Jevons ter escrito qualquer coisa, e sua contribuição 
limitou-se, basicamente, a mostrar que o marginalismo permitia que as idéias de Malthus, Say, Senior e Bastiat fossem apresentadas com elegância matemática e maior coerência lógica. Mas a essência teórica e ideológica da perspectiva da utilidade permaneceu inalterada. (ibid.)

O tratamento dado ao marginalismo é severamente irônico e desabonador. Hunt, imputa aos autores um objetivo consciente de manutenção do status quo.

Em contraposição temos a postura de Rima que exalta o pensamento marginalista, afirmando que

[na década de 1870] a análise econômica foi revolucionada pela introdução de um novo ponto de vista de um novo instrumento poderoso. O novo ponto de vista dizia respeito ao papel da utilidade na determinação do valor; e o novo instrumento era o conceito do incremento adicional ou marginal. (...) Seu descobrimento e a precisão desenvolvida em seu uso deram ao economista um instrumento analítico que desde então se tornou indispensável. (RIMA, 1977, p. 247)

Schumpeter, por sua vez, procura fazer uma análise diferente avaliando o marginalismo enquanto instrumento de análise e, neste sentido, aponta como benefício desta linha de pensamento o fato de possuir aplicabilidade geral aos problemas econômicos (SCHUMPETER, 1964, v. 3, p. 189). Blaug procura assumir uma postura crítica admitindo a grande influência que a teoria neoclássica teve no desenvolvimento posterior da ciência econômica. Segundo ele, esta teoria englobaria mais que o sistema clássico anterior em certos aspectos (como maior generalidade e brevidade de raciocínio ao explicar os preços dos fatores e dos produtos a partir de um único e mesmo princípio) e noutros não (diz que só raramente uma maior generalidade representa uma vantagem indiscutível, e num certo sentido a teoria neoclássica é mais restritiva do que a teoria clássica, como quanto a oferta de trabalho) (BLAUG, 1990, 2 v., p. 22). Ao final Blaug afirma: "Um crítico pouco complacente poderia dizer que a economia neoclássica atingiu, efectivamente, um grau superior de generalidade, mas apenas porque são mais fáceis as questões a que responde" (ibid., p. 23). Parece, dessa forma, se contrapor à observação de Schumpeter citada acima, mas isto não é de todo verdadeiro se lembrarmos que Schumpeter coloca como ápice da contribuição da revolução marginalista a teoria do equilíbrio de Walras, desde que observada como teoria pura. 
Rima refere-se aos primeiros passos na construção do conceito de utilidade marginal dizendo que "seus esforços embrionários não produziram frutos; de fato, como acontece tantas vezes, as verdades essenciais tiveram de ser redescobertas por outros antes que fossem incorporadas à análise econômica" (RIMA, 1977, p. 262). Apesar de tratar de verdades no plural, resta saber se encontra em correntes muito diferentes do marginalismo também alguma verdade. Para esclarecer esta possível dúvida, encontramos outro trecho de Rima: "O interesse dos economistas clássicos pelo problema do valor de troca como sua falha em não perceberem qualquer relacionamento entre valor de uso e valor de troca fez com que negligenciassem o papel da utilidade e da procura na determinação de preços" (RIMA, 1977, p. 247). Aqui temos um reforço da idéia de que Rima parece simpatizar com o marginalismo, já que conclui como falha a dissociação entre valor de troca e de uso. Já Denis deixa explícita sua idéia de verdade na teoria do valor: "É, pois, evidente que a lei levantada por Jevons não nos traz, em si mesma, nada que possa ajudar-nos a explicar os fenômenos reais." (DENIS, 1982, p. 514). E comenta: "Na realidade, seria necessário afirmar: a quantidade de trabalho determina o preço a que a mercadoria é oferecida. Mas esta rectificação bastaria para restabelecer a verdadeira teoria do valor" (DENIS, 1982, p. 515). Denis não discute de maneira mais abrangente a simultaneidade das idéias, mas afirma que, pelo dos livros de Jevons e Menger aparecerem no mesmo ano, "pode-se afirmar que elas constituem uma descoberta realizada simultaneamente pelos dois autores" (ibid., p. 523). Com relação ao livro de Walras diz: “...não parece que, ao redigi-lo, o autor tenha tido conhecimento dos trabalhos de Jevons e Menger. Eis por que se admite geralmente que a teoria marginalista do valor teve três fundadores." (ibid.).

A leitura de Galbraith salienta a diferença no tratamento dado pelos manuais à chamada revolução marginalista, pois ele apresenta outros nomes como pensadores principais: Jevons, Menger e John Bates Clark. Segundo ele, estes autores deram um grande passo ao reconhecer aquilo que até hoje os livros-texto celebram: o papel, não da utilidade geral, mas da utilidade marginal (GALBRAITH, 1989, p. 97). Léon Walras é citado apenas de maneira secundária em dois momentos. Primeiro, na página 97, como filho de Auguste Walras e depois, na página 111, quando Pareto está sendo focado (já que este sucedeu Walras na universidade de Lausanne). Ainda, Galbraith não usa o termo revolução para a contribuição destes três autores no ressurgimento do marginalismo. 


\section{CONSIDERAÇÕES FINAIS}

Da observação dos seis livros de HPE percebe-se que seus autores não escrevem de maneira "imparcial" ou apenas "técnica"; pelo contrário, expressam suas crenças, simpatias e críticas com relação aos temas focados neste trabalho, quais sejam: pensamento de Nassau Senior e Revolução Marginalista. Ampliando as conclusões destes dois focos para o conteúdo dos manuais de HPE, podemos dizer que existem elementos nos discursos dos autores dos livros-texto que os diferenciam e proporcionam significados distintos aos pensamentos econômicos apresentados, fruto de interpretações individuais com relação ao mesmo tema. Tipicamente o autor do livro-texto faz escolhas retóricas e de estilo que adicionam um caráter de certeza factível e de convencimento ao fenômeno que está sendo descrito. As conseqüências são paradoxais. Por um lado, esta postura torna mais fácil a leitura pelo aluno de graduação. Por outro lado, torna mais difícil a experiência com leituras de outros tipos de texto que os estudantes encontrarão mais à frente na carreira acadêmica e em seus próprios textos universitários. Mesmo sendo controversa a dinâmica dos pensamentos econômicos ao longo da história, a ausência desta discussão nos cursos de HPE pode resultar numa aceitação passiva pelo aluno do que ele lê. Neste sentido, pode-se impossibilita uma reflexão mais profunda sobre o caráter do que é aceito como "verdade" na ciência e especificamente na economia. Os textos originais e os manuais, exatamente por sua característica interpretativa, poderiam ser utilizados como material para aguçar a postura crítica dos discentes frente à Economia.

\section{RESUMO}

Este trabalho analisa seis manuais de História do Pensamento Econômico (HPE) muito utilizados no ensino de graduação no país: "História do Pensamento Económico" de Mark Blaug, "História do Pensamento Económico" de Henri Denis, "O Pensamento Econômico em Perspectiva - uma história crítica" de J. K. Galbraith, "História do Pensamento Econômico" de E. K. Hunt, "História do Pensamento Econômico" de I. H. Rima, "História da Análise Econômica" de J. A. Schumpeter. O intuito é discutir como os autores destes livros explicitam diferentes objetivos e posturas frente à HPE e vão se diferenciar na apresentação de um evento na história das idéias econômicas e no tratamento dado ao pensamento de um determinado 
autor. Para tanto, escolheu-se a Revolução Marginalista como o evento a ser estudado e o pensamento de Nassau Senior. Pôde-se observar que tipicamente o autor do livro-texto faz escolhas retóricas e de estilo que adicionam o caráter de certeza factível e de convencimento ao fenômeno que está sendo descrito. No entanto, o tratamento dado aos fenômenos se diferencia. Dessa constatação emergem reflexões sobre o material bibliográfico utilizado e a maneira de ensinar a HPE. Palavras-chave: História do Pensamento Econômico, ensino, Revolução Marginalista, Nassau Senior.

\begin{abstract}
This paper analyses six handbooks of History of Economic Thought (HET), which are adopted in the Brazilian undergraduate courses: "History of Economic Thought" by Mark Blaug; "History of Economic Thought" by Henri Denis; "Economics in Perspective: a Critical History" by J. K. Galbraith; "History of Economic Thought" by E. K. Kunt; "History of Economic Thought" by I. H. Rima; and "History of Economic Analysis" by J. A. Schumpeter. The main objective of this paper is to investigate how these authors show distinct purposes and positions towards HET, being their presentations about the course of events in the history of economic ideas as well as their approaches to the reading of specific authors completely different from each other. In this regard, the Marginalist Revolution and the Nassau Senior's thought were chosen as the main subjects to be analysed. This paper concludes that those authors usually make rhetoric and stylistic choices in order to give to those described phenomenona a convincing character, although their approaches to the phenomenona are very different. From this conclusion, some considerations are taken in relation to the adopted bibliography and the way of teaching HET as well.

Key-words: History of economic thought, teaching, Marginalist Revolution, Nassau Senior.
\end{abstract}




\section{REFERÊNCIAS}

BLAUG, M. História do pensamento econômico. Lisboa: Dom Quixote, 1990. 1. ed. 1962, 1. ed. 1990, v. 1 e 2.

DAVIS, J. B.; HANDS, D. W.; MAKI, U. The handbook of economic methodology, USA: Edwards Elgar, 1998.

DENIS, H. História do pensamento econômico. 4. ed. Livros Horizonte, 1982.

FEIJÓ, R., BARBIERI, F. Reflexões sobre o ensino de história do pensamento econômico no Brasil, 2000. Mimeografado.

FONSECA, E. G. Reflexões sobre a historiografia do pensamento econômico. In: ENCONTRO NACIONAL DE ECONOMIA, 22., dez. 1994, Florianópolis. Anais... v. 1, p. 553-572.

GALBRAITH, J. K. O pensamento econômico em perspectiva - uma história crítica. São Paulo: Pioneiras, 1989.

HUNT, E. K. História do pensamento econômico. 7. ed. [S.1.]: Campus, 1989.

POPPER, K. R. A Sociedade Aberta e seus inimigos. São Paulo: Abril Cultural, 1980.

RIMA, I. H. História do pensamento econômico. [S.1.]: Atlas, 1977. (1. ed. em inglês 1972).

SCHUMPETER, J. A. História da análise econômica. Rio de Janeiro: Centro de Publicações Técnicas da Aliança, 1964.

SWALES, J. M The paradox of value: six treatments in search of the reader. In: HENDERSON, W.; DUDLEY-EVANS, T.; BACKHOUSE, R. (Eds.). Economics \& Language Routledge, p. 223-239, 1993.

ZERKOWSKI, R. M. History of economic analysis: 30 anos depois. Revista de Administração Pública, Rio de Janeiro, p. 119-132, jan./mar. 1987. 